\title{
Serum $\alpha_{2}$-macroglobulin levels in diabetes
}

\author{
K JAMES ${ }^{1}$, J MERRIMAN', RS GRAY ${ }^{2}$, LJP DUNCAN', AND R HERD 3 \\ From the ${ }^{1}$ Department of Surgery, University of Edinburgh Medical School, Teviot Place, Edinburgh \\ EH8 9AG, ${ }^{2}$ Diabetic and Dietetic Department, Royal Infirmary, Lauriston Place, Edinburgh EH3 $9 Y W$, \\ and ${ }^{3}$ Medical Computing and Statistics Unit, University of Edinburgh Medical School, Teviot Place, \\ Edinburgh EH8 $9 A G, U K$
}

SUMMARY Serum $\alpha_{2}$-macroglobulin levels have been determined in diabetic patients by quantitative radial immunodiffusion and compared with those observed in age- and sex-matched controls. In addition, the results in diabetics have been analysed with respect to such variables as the age and sex of the patient, the duration of disease, treatment, control, and the occurrence of retinopathy or nephropathy.

The $\alpha_{2}$-macroglobulin levels in diabetic patients were found to be significantly higher than in ageand sex-matched controls, thus confirming previous observations. However, these differences were most apparent in the more extreme age groups. Multiple regression analysis also revealed that the only variables contributing significantly to the regression apart from age and sex were control and retinopathy.

Although there have been a number of reports indicating that serum $\alpha_{2}$-macroglobulin levels may be elevated in diabetes, few of these studies have taken into consideration the known variation in the level of this protein with age and sex, ${ }^{1}$ or the possible influence of any therapy employed, or the duration of the disease.

In view of these limitations we decided to undertake further studies of serum $\alpha_{2}$-macroglobulin levels in diabetic patients. Furthermore, such studies seemed desirable in the light of recent suggestions that the incidence of peripheral vascular complications in diabetic patients might be linked to high serum $\alpha_{2}$-macroglobulin levels, ${ }^{2}$ and the report that this protein is intimately associated with human vascular endothelium. ${ }^{3}$

\section{Material and methods}

PATIENTS AND CONTROLS

The diabetic patients studied were regularly attending the Diabetic and Dietetic Department of the Royal Infirmary, Edinburgh. Further details on the number of patients treated with diet, oral hypoglycaemic agents, and insulin, their ages, and the duration of diabetes in relation to treatment are rezorded in Table 1.

Received for publication 29 August 1979
Table 1 Patients studied according to sex, treatment, age, and duration of diabetes

\begin{tabular}{|c|c|c|c|c|}
\hline Treatment & Sex & $\begin{array}{l}\text { No. of } \\
\text { patients }\end{array}$ & Age $(y r)$ & Duration (yr) \\
\hline Diet & $\begin{array}{l}\mathbf{M} \\
\mathbf{F}\end{array}$ & $\begin{array}{l}36 \\
17\end{array}$ & $54 \cdot 6 \pm 12 \cdot 7$ & $3.8 \pm 4.0$ \\
\hline OHA & $\begin{array}{l}\mathbf{M} \\
\mathbf{F}\end{array}$ & $\begin{array}{l}44 \\
37\end{array}$ & $59.8 \pm 13.5$ & $6 \cdot 0 \pm 5 \cdot 3$ \\
\hline Insulin & $\begin{array}{l}\mathbf{M} \\
\mathbf{F}\end{array}$ & $\begin{array}{l}46 \\
46\end{array}$ & $41 \cdot 3 \pm 17 \cdot 2$ & $10 \cdot 8 \doteq 9 \cdot 1$ \\
\hline
\end{tabular}

Diabetic control was assessed on the basis of the mean plasma glucose concentration observed at the time of study and the previous two outpatient attendances at the clinic. Mean plasma glucose levels of $<9,9-14,>14 \mathrm{mmol} /$ litre were regarded as indicating good, moderate, and poor control respectively.

The ocular fundi of each patient were examined under clinic conditions, and retinopathy status was recorded as DR-negative (no retinopathy or mild background retinopathy) or DR-positive (moderate to extensive background retinopathy with or without new vessel formation).

A urine sample was obtained from all patients at every clinic attendance and tested for protein using Multistix (The Ames Co, Slough, UK). Those without proteinuria were considered to have no nephropathy (ie, grade 0 ), while those with intermittent or 
persistent proteinuria were considered to have grades 1 and 2 nephropathy respectively.

The normal human serum samples (ages 18-70) were freshly collected by the Blood Transfusion Service, The Royal Infirmary, Edinburgh. The older controls were obtained from geriatrics with no apparent clinical abnormalities. All serum samples were stored at $-20^{\circ} \mathrm{C}$ before assay.

ESTIMATION OF $\alpha_{2}$-MACROGLOBULIN

Serum $\alpha_{2}$-macroglobulin levels (expressed as mg per dl) were measured by a standard Mancini gel diffusion method. ${ }^{4} \mathrm{~A}$ range of $\alpha_{2}$-macroglobulin standards were included on every plate, and all samples were assayed in duplicate. The standard serum had been calibrated against a human $\alpha_{2^{-}}$ macroglobulin reference standard obtained from Meloy Laboratories Inc, Springfield, Virginia, USA. The antiserum to human $\alpha_{2}$-macroglobulin was produced in rabbits as previously described. ${ }^{5}$

\section{STATISTICAL ANALYSES}

The results obtained were submitted to a number of statistical analyses. Initially, the levels of $\alpha_{2^{-}}$ macroglobulin in diabetics were compared with those observed in age- and sex-matched normal controls using both Student's $t$ test and Welch's test, which allows for differences in variance. As preliminary analysis indicated that the significance levels obtained by both tests were similar, the data were subsequently analysed by conventional procedures. The values obtained in diabetics were also subjected to both individual and multiple regression analysis of $\alpha_{2} \mathbf{M}$ values on sex, age, treatment, control, duration, retinopathy, and nephropathy.

\section{Results}

An overall analysis of the results indicated that serum $\alpha_{2}$-macroglobulin levels were significantly higher $(P<0.001)$ in diabetics than in normals, thus confirming the results of previous observations. ${ }^{16}$ However, in the present study, additional points emerged. Thus while $\alpha_{2}$-macroglobulin levels in diabetics also varied with age, the pattern of variation was somewhat different from that noted in normals (Fig. 1; Table 2). These differences were most apparent in the younger and older patients, the $\alpha_{2-}$ macroglobulin levels in the 41-50 age group being relatively similar. It should perhaps be noted that while the data in Table 2 suggest that these differences are more apparent in female diabetics we believe that this is simply a reflection of small sample sizes.

The results obtained in diabetic patients were subjected to further analyses. Initially, the $\alpha_{2}$ macroglobulin levels were regressed on each of the variables individually in turn. From these preliminary analyses each variable appeared significantly to influence the $\alpha_{2}$-macroglobulin level in diabetics (Table 3). Thus, as in normal controls, the levels of this protein were significantly higher in both females and males and there was a significant quadratic relationship with age. Furthermore, significant differences were noted with respect to such variables as

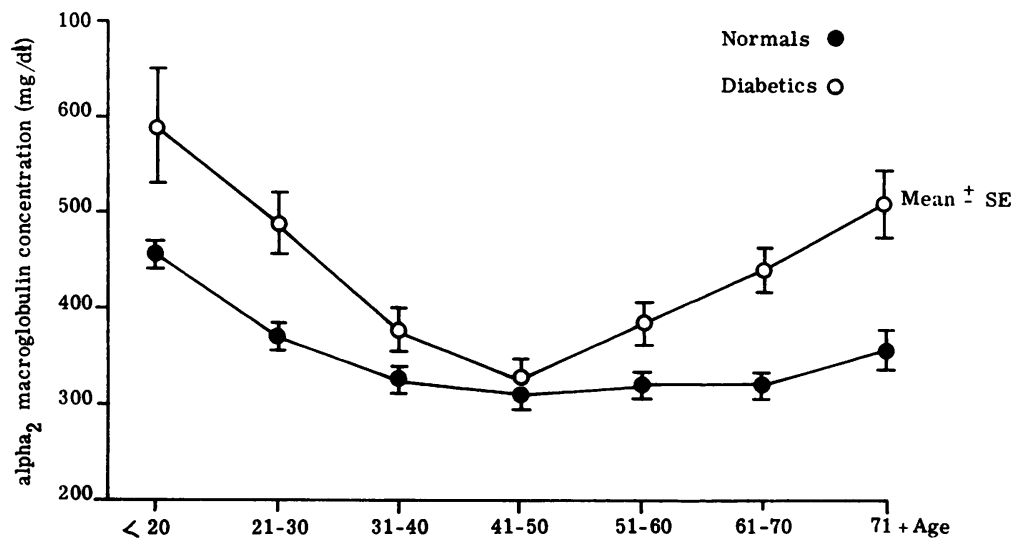

The values observed in male and female diabetics have been pooled and compared with those in pooled normal controls. Note that in both groups the $a_{2}$-macroglobulin levels exhibit a quadratic variation with age, but the pattern in diabetics is somewhat different from that in normals. Thus the levels of this protein in diabetics appear to be most significantly elevated above control values in the younger and older age groups, while those in the 41-50 range are not significantly different from normal. 
Table 2 Levels of $a_{2}$-macroglobulin in diabetic patients and sex-and age-matched controls

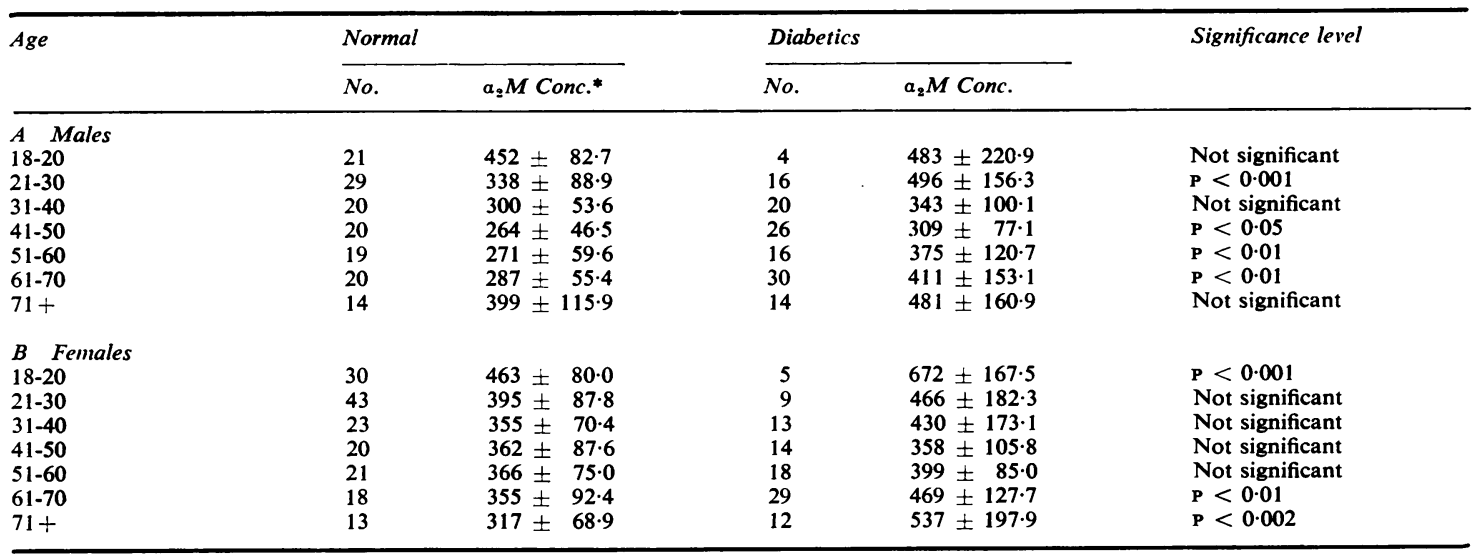

*Arithmetic mean value \pm standard deviation (mg per $\mathrm{dl})$.

the duration of the diseise, the form of treatment, the degree of control, and the incidence of retinopathy. However, it should be noted that where multiple comparisons are being made (Tables 2 and 3) small $P$ values $(\mathrm{eg}, 0.05)$ are not necessarily significant.

When more detailed analyses of these results were undertaken, namely, multiple regression analysis, it became apparent that the only variables contributing significantly to the regression, apart from age $(\mathrm{P}<0.001)$ and sex $(\mathrm{P}<0.05)$, were control $(\mathrm{P}<$ $0.025)$ and retinopathy $(P<0.001)$. The actual regression equation was as follows:

$Y=935 \cdot 8+42 \cdot 8$ (if female) $-2 \cdot 310 \times$ Age $+0 \cdot 2387$ $\times{\text { (Age })^{2}}^{2}$

$- \begin{cases}54 \cdot 38 \text { if moderate control }+ & 91 \cdot 85 \text { (if } \\ 85 \cdot 53 \text { if good control } & \text { retinopathy }+\mathrm{ve})\end{cases}$ where $Y$ is the $\alpha_{2} \mathrm{M}$ level.

\section{Discussion}

The present results confirm those of previous workers, indicating that $\alpha_{2}$-macroglobulin levels are elevated in diabetic patients. ${ }^{6}$ ? They also reemphasise that, as in normal individuals, the level of $\alpha_{2}$-macroglobulin in diabetics is significantly influenced by the sex and age of the patient ${ }^{7}$ though the pattern of variation with age may be different from that in normal controls.

However, of most interest in relationship to the present study are the results of multiple regression analysis, which indicate the variables most significantly influencing the regression in diabetics. Apart from sex and age, these appear to be the control of blood sugar level and the presence of retinal complications. All the other variables studied,

Table 3 Influence of various factors on $a_{2}$-macroglobulin levels in diabetic patients-a summary of individual regression analysis on each variable

\begin{tabular}{|c|c|c|c|}
\hline Variable investigated & No. of samples & $\alpha_{2} M^{*}$ concentration & Significance level \\
\hline Age $\quad\left\{\begin{array}{l}\text { Linear } \\
\text { Quadratic }\end{array}\right.$ & 226 & & $P<0.001$ \\
\hline $\begin{array}{l}\text { Male } \\
\text { Female } \\
\text { Positive }\end{array}$ & $\begin{array}{l}126 \\
100\end{array}$ & $\begin{array}{l}395 \pm 145 \cdot 5 \\
454 \pm 156 \cdot 1\end{array}$ & $P<0.005$ \\
\hline $\begin{array}{l}\text { Positive } \\
\text { increase }\end{array}$ & & & $P<0.001$ \\
\hline Treatment & $\begin{array}{l}53 \\
81 \\
92 \\
21\end{array}$ & $\begin{array}{l}358 \pm 106.1 \\
409 \pm 161.9 \\
468 \pm 153.6 \\
388 \pm 164.9\end{array}$ & $P<0.001$ \\
\hline Control & $\begin{array}{r}107 \\
98 \\
183\end{array}$ & $\begin{array}{l}433 \pm 156 \cdot 7 \\
519 \pm 135 \cdot 4 \\
401 \pm 141 \cdot 6\end{array}$ & $\begin{array}{l}\mathbf{P}<0.005 \\
\mathbf{P}<0.001\end{array}$ \\
\hline Retinopathy $\left\{\begin{array}{l}\text { Zero } \\
\text { Positive }\end{array}\right.$ & $\begin{array}{r}43 \\
217\end{array}$ & $\begin{array}{l}506 \pm 170 \cdot 1 \\
417 \pm 150 \cdot 2\end{array}$ & \\
\hline Nephropathy $\left\{\begin{array}{l}1 \\
2\end{array}\right.$ & $\begin{array}{l}7 \\
2\end{array}$ & $\begin{array}{l}481 \pm 157 \cdot 9 \\
660 \pm 294 \cdot 9\end{array}$ & $P<0.05$ \\
\hline
\end{tabular}

*Arithmetic mean value \pm standard deviation (mg per $\mathrm{dl}$ ). 
including duration of disease, treatment, and nephropathy, were not independent of the above and so became redundant. In short they failed to contribute significantly to the regression.

These observations indicate that there is a strong association between poor control and high $\alpha_{2}$-macroglobulin levels. Likewise, there is a similar association between high levels of this protein and the incidence of diabetic retinopathy, an observation noted by other workers using less sophisticated statistical analyses. ${ }^{8}$ However, in contrast to the present observations, others have noted that the elevation of $\alpha_{2}$-macroglobulin levels in diabetics is directly related to the duration of the disease ${ }^{7}$ and is not significantly different in patients with vascular complications apart from nephropathy. ${ }^{79}$

The present results indicate that the determination of $\alpha_{2}$-macroglobulin levels in diabetic patients may provide useful additional information with respect to both the ease with which control of blood sugar levels can be achieved and the propensity to develop retinal complications. It is appreciated, however, that more detailed studies on larger groups of patients will be necessary to establish unequivocally the true relevance of these observations and the biochemical events leading to these perturbations. Nevertheless the present observations, together with the known biochemical ${ }^{10} 11$ and possible immunological properties of $\alpha_{2}$-macroglobulin, ${ }^{12}$ emphasise that this is an area worthy of further investigation.

We thank Dr A E Robertson and her staff, of the Blood Transfusion Service, Edinburgh, for providing the normal human serum samples. We are also grateful to Dr R Elton, of the Medical Computing and Statistics Unit, for his help and advice.

\section{References}

${ }^{1}$ Ganrot PC, Schersten B. Serum alpha ${ }_{2}$-macroglobulin concentration and its variation with age and sex. Clin Chim .Acta 1967;15:113-20.
${ }^{2}$ Brownlee M. Alpha ${ }_{2}$-macroglobulin and reduced basement-membrane degradation in diabetes. Lancet 1976;1:779-80.

${ }^{3}$ Becker CG, Harpel PC. Alpha ${ }_{2}$-macroglobulin on human vascular endothelium. J Exp Med 1976;144: $1-9$.

${ }^{4}$ Mancini G, Carbonara AO, Heremans JF. Immunochemical quantitation of antigens by single radial immunodiffusion. Immunochemistry 1965;2:235-54.

${ }^{5}$ Tunstall AM, Merriman JML, Milne I, James K. Normal and pathological serum levels of $\alpha_{2}$-macro- . globulins in men and mice. J Clin Pathol 1975;28: 133-9.

${ }^{6}$ James K, Johnson G, Fudenberg HH. The quantitative estimation of alpha ${ }_{2}$-macroglobulin in normal, ? pathological and cord sera. Clin Chim Acta 1966; 14:207-14.

7 Ganrot PO, Gydell K, Ekelund H. Serum concentra- $\vec{\sigma}$ tion of alpha $a_{2}$-macroglobulin, haptoglobin and $\omega$ alpha ${ }_{1}$-antitrypsin in diabetes mellitus. Acta Endo- 을 crinol 1967;55:537-44.

${ }^{8}$ Cleve H, Alexander K, Mitzkat HJ, Nissen P, Salzmann 7 , I. Serumglykoproteine beim Diabetes mellitus; 응 quantitative immunologische Bestimmung von saurem $a_{1}$-Glykoprotein, Gc, $a_{2}$-Makroglobulin und $\stackrel{\varrho}{2}$ Hämopexin bei Diabetikern mit und ohne Angiopathien. Diabetologica 1968;4:48-55.

$\checkmark$ McMillan DE. Alpha ${ }_{2}$-macroglobulin in diabetes (Letter). Lancet 1976;2:1020-1.

${ }^{10}$ Harpel PC. Alpha $a_{2}$-macroglobulin. In: Bing DH, ed. The Chemistry and Physiology of the Human Plasma Proteins. New York: Pergamon Press, 1979.

${ }^{11}$ Starkey PM, Barret AJ. Alpha ${ }_{2}$-macroglobulin, a physiological regulator of proteinase activity. In: $\mathbb{Q}$ Barrett AJ, ed. Proteinases in Mammalian Cells and $\overrightarrow{\vec{B}}$ Tissue. Amsterdam: North Holland, 1977:663-96.

12 James K. Alpha ${ }_{2}$-macroglobulin and its association $\frac{3}{5}$ with the immune system. Trends in Biochemical Sciences 1979 (In press).

Requests for reprints to: Dr Keith James, Department of Surgery, University Medical School, Teviot Place, Edinburgh EH8 9AG, UK. 